\title{
Determinação da composição físico-química de produtos lácteos: estudo exploratório de comparação dos resultados obtidos por metodologia oficial e por ultra-som
}

\author{
Raphael Costa Venturoso, Keila Emílio de Almeida, Alexandre Mariani Rodrigues, \\ Maria Regina Damin, Maricê Nogueira de Oliveira* \\ Departamento de Tecnologia Bioquímico-Farmacêutica, Faculdade de Ciências Farmacêticas, \\ Universidade de São Paulo
}

*Correspondência:

Maricê Nogueira de Oliveira Departamento de Tecnologia Bioquímico-Farmacêutica

Faculdade de Ciências Farmacêuticas - USP

Av. Prof. Lineu Prestes, 580

05508-000 - São Paulo - SP, Brasil E-mail: monolive@usp.br
O presente trabalho tem como objetivo comparar os métodos oficiais de determinação físico-química de produtos lácteos (extrato seco desengordurado, proteína, gordura e densidade) com metodologia de ultra-som. Foram analisados diferentes leites (integral e desnatado, convencional e orgânico), leites fermentados comerciais, bases lácteas para leites fermentados e soro de queijo, totalizando vinte produtos lácteos de características diferentes. $O$ método por ultra-som é rápido e os resultados obtidos correlacionam-se àqueles das análises oficiais. Entretanto, é necessário o emprego de um perfil específico através da calibração do equipamento com base nas informações das análises oficiais. Os resultados deste trabalho exploratório sugerem a necessidade de se realizar um estudo com grande número de amostras a fim de validar as conclusões obtidas. As evidências descritas neste artigo são importantes para a indústria brasileira de produtos lácteos.

\author{
Unitermos \\ - Leite \\ - Produtos lácteos \\ - logurte \\ - Qualidade físico-química \\ - Ultra-som
}

\section{INTRODUÇÃO}

O controle de qualidade do leite e dos produtos lácteos é de fundamental importância para a garantia da saúde da população. A qualidade pode ser avaliada através de determinações físicas, químicas, microbiológicas, sensoriais e provas de higiene. A composição química deve ser sempre analisada nos laticínios e nas indústrias em razão dos padrões mínimos exigidos pelo Ministério da Agricultura, Pecuária e Abastecimento. Algumas usinas de beneficiamento já iniciaram programas de pagamento do leite aos produtores em função da qualidade do mesmo. Desta forma, o uso de novas tecnologias para facilitar a avaliação da qualidade do leite mediante análises químicas rápidas e confiáveis torna-se muito interessante.

O conhecimento da composição química do leite é fator de suma importância para a fabricação de produtos lácteos fermentados ou não. Existem vários métodos bem estabelecidos para as determinações físico-químicas dentre os quais aqueles adotados pela legislação vigente como sendo oficiais (Brasil, 2003). Os métodos oficiais exigem tempo, mão-de-obra treinada e requerem reagentes caros para sua execução.

As técnicas de ultra-som estão sendo cada vez mais aplicadas na indústria para análise e modificação de alimentos (McClements, 1995). Em equipamentos modernos, as 
medidas das propriedades ultra-sônicas da amostra, tais como velocidade ultra-sônica, coeficiente de atenuação, impedância ultra-sônica, podem ser usadas para determinar a composição química dos produtos lácteos e calcular o índice crioscópico (Poovey, Mason, 1998). Extensivos estudos foram realizados com a utilização de propriedades ultrasônicas do leite para determinar os conteúdos de gordura e sólidos totais. $\mathrm{O}$ instrumento usa ondas de som de freqüência extremamente alta (acima da percepção humana) para obter resultados. Em princípio, faz uso do fato que a velocidade das ondas de ultra-som em água aumenta proporcionalmente com a temperatura da amostra até cerca de $75^{\circ} \mathrm{C}$. Os sólidos dissolvidos na água produzem aumento na velocidade do som. Este, quando comparado com aquele da água pura, pode ser diretamente correlacionado com os sólidos totais em dada temperatura. Por outro lado, a gordura irá produzir o efeito oposto. A velocidade do som irá decrescer tanto quanto o teor de gordura aumenta na faixa de temperatura considerada. $\mathrm{O}$ efeito da gordura láctea pode ser eliminado se a medida é feita a $14{ }^{\circ} \mathrm{C}$. Duas células de amostra mantidas a diferentes temperaturas específicas podem ser utilizadas para determinações simultâneas de gordura e sólidos totais. As análises não destrutivas levam menos de um minuto por amostra (Atherton, Newlander, 1981). Além de ser automática a tecnologia apresenta vantagens tais como: as medidas são efetuadas diretamente nas amostras de leite refrigerado $\left(5^{\circ} \mathrm{C}\right)$, a precisão da medida não depende da acidez do leite, não utiliza reagentes e pode ser utilizado para qualquer tipo de leite fluido (Lactoscan, 2006). Não existem dados na literatura sobre o uso desta metodologia em leites fermentados.

Este trabalho tem como objetivo comparar os métodos oficiais de determinação de extrato seco desengordurado, proteína, gordura e densidade com metodologia de ultra-som na análise de vários produtos lácteos como leites de origem convencional e orgânica, leites fermentados comerciais, bases lácteas para leites fermentados e, soro de queijo.

\section{MATERIAL E MÉTODOS}

\section{Material}

Vinte produtos lácteos foram utilizados tendo sido escolhidos em função de suas características físico-químicas, natureza, sua composição fundamental e importância. São eles:

- Leites integrais convencionais (LCI1 e LCI2);

- Leites integrais orgânicos (LOI1 e LOI2);

- Leites desnatados convencionais (LCD1 e LCD2);

- Leites desnatados orgânicos (LOD1 e LOD2);

- Soro de queijo Minas Frescal (S1 e S2). O soro de queijo foi obtido da elaboração do queijo tipo Minas
Frescal, conforme a metodologia especificada por Furtado, Neto (1994).

- Leites fermentados comerciais (Y, Fp e M);

- Bases lácteas para leites fermentados elaboradas em laboratório com leites padronizados a $12,0 \%$ de sólidos totais com leite em pó desnatado (LPD) e enriquecidos com hidrolisado de caseína (HC), LPD e proteína concentrada de soro (PCS), segundo desenho experimental simplex centróide. A adição de fatores de crescimento auxilia no crescimento das bactérias probióticas em leite durante a fermentação para produção de bebidas lácteas probióticas. As proteínas lácteas hidrolisadas ou concentradas são alguns dos fatores que estimulam o crescimento dos probióticos (Oliveira et al., 2001). Com o objetivo de estudar o efeito simultâneo da suplementação do leite com hidrolisado de caseína, proteína concentrada de soro e leite em pó desnatado empregou-se um delineamento de mistura simplex centróide com sete experimentos, que resultou nas bases lácteas para leites fermentados. Os percentuais de LPD, HC e PCS em cada amostra foram os seguintes: BL1 $(1,2 \% \mathrm{HC})$; BL2 $(0,6 \%$ PCS $+0,6 \%$ LPD); BL3 (0, $6 \%$ HC + 0,6\% LPD); BL4 ( $0,4 \%$ $\mathrm{HC}+0,4 \% \mathrm{LPD}+0,4 \% \mathrm{LPD}) ; \mathrm{BL} 5$ (1,2\% LPD); BL6 $(0,6 \% \mathrm{HC}+0,6 \% \mathrm{PCS}) ; \mathrm{BL} 7$ (1,2\% PCS).

\section{Métodos}

\section{Análises físico-químicas oficiais}

Extrato seco total e desengordurado: a determinação do extrato seco total foi realizada em estufa a $102 \pm 2{ }^{\circ} \mathrm{C}$, até peso constante. $\mathrm{O}$ extrato seco desengordurado foi calculado pela diferença entre o teor do extrato seco total da amostra e seu respectivo teor de lipídios.

Proteína: a proteína bruta foi calculada em função dos teores de nitrogênio total determinado pelo método de micro Kjeldahl, multiplicado pelo fator 6,38.

Lipídios: o teor de lipídios determinado pelo método de Gerber.

Densidade: as determinações de densidade dos diferentes leites e soro de queijo foram realizadas por termolacto-densímetro de Quevenne, com escala entre 1,015 a 1,040 g.cm ${ }^{-3}$.

Todas as análises físico-químicas foram realizadas de acordo com a metodologia oficial descrita em BRASIL (2003).

\section{Análises físico-químicas por ultra-som}

Foram determinados extrato seco desengordurado, proteína, gordura e densidade em equipamento EkoMilk, EON Trading \& Bulteh 2000, Stara Zagora, Bulgária pelo método de análise por ultra-som calibrado em dois perfis 
diferentes (Perfil 1 e Perfil 2, equivalentes a leite pasteurizado e cru, respectivamente).

\section{Análise estatística}

Todas as análises foram realizadas em triplicata. Os resultados de extrato seco desengordurado, proteína e gordura foram expressos em g. $100 \mathrm{~g}^{-1}$ e de densidade em g. $\mathrm{cm}^{-3}$. Estes foram submetidos à Análise de Variância (ANOVA) e teste de Tukey para comparação de médias. A fim de se identificar a relação entre o dois métodos procedeu-se à correlação de matrizes entre os resultados considerando-se um nível de significância $P \leq 0,05$.

\section{RESULTADOS E DISCUSSÃO}

Os resultados das análises físico-químicas dos diferentes produtos lácteos obtidos através dos diferentes métodos estão apresentados nas Tabelas I e II. A natureza da amostras e sua composição fundamental podem, ou não, influenciar nos resultados finais. O aparelho utilizado neste estudo é polivalente - executa diversas análises simultaneamente e em dois perfis de calibração, isto é perfis 1 e 2 , respectivamente. Cada análise demonstra uma peculiaridade - seja por ser válida em ambos ou em apenas um dos perfis; conflitar com outra propriedade da amostra, ou ain- da por não se enquadrar nas quantificações reais, feitas em laboratório.

\section{Extrato seco desengordurado}

A quantificação do extrato seco desengordurado apresentou a principal característica conflitante entre os resultados do método oficial e do aparelho ultra-som. O extrato seco desengordurado variou estatisticamente para os diferentes leites entre 7,92 g. $100 \mathrm{~g}^{-1}$ a 9,63 g.100 g-1 (Tabela I). Estes valores estão dentro da faixa encontrada por Garrido et al. (2001) analisando leites integrais da região de Ribeirão Preto, São Paulo. Gonzalez et al. (2004) quantificaram como $8,52 \pm 0,46$ g. $100 \mathrm{~g}^{-1}$ o extrato seco desengordurado do leite do leite da bacia leiteira de Pelotas, Rio Grande do Sul enquanto Duarte et al. (2005) encontraram 9,27 g.100 g-1 o extrato seco desengordurado do leite oriundo de vacas Jersey alimentadas com concentrado sem gordura.

Para o soro de queijo, o extrato seco desengordurado variou de 6,20 a 7,05 g. $100 \mathrm{~g}^{-1}$ (Tabela I). Resultados semelhantes foram obtidos por Prudêncio, Benedet (1999) e Almeida (2005).

Os diferentes leites fermentados apresentaram extrato seco desengordurado variando de 13,9 a 19,68 g.100 g-1 (Tabela II). O teor de sólidos (incluindo sólidos gordurosos)

TABELA I - Teores de extrato seco desengordurado (g.100g-1), proteína (g.100g-1), lipídios $\left(\mathrm{g} .100 \mathrm{~g}^{-1}\right)$, e densidade $\left(\mathrm{g} . \mathrm{cm}^{-3}\right)$ em leites integrais convencionais (LCI1 e LCI2), leites integrais orgânicos (LOI1 e LOI2), leites desnatados convencionais (LCD1 e LCD2), leites desnatados orgânicos (LOD1 e LOD2) e soro de queijo Minas Frescal (S1 e S2) obtidos por métodos oficiais e por técnica de ultra-som em dois perfis (Perfil 1 e Perfil 2)

\begin{tabular}{|c|c|c|c|c|c|c|c|c|c|c|c|}
\hline & & LCI1 & LCI2 & LOI1 & LOI2 & LCD1 & $\mathrm{LCD} 2$ & LOD1 & LOD2 & $\mathrm{S} 1$ & $\mathrm{~S} 2$ \\
\hline $\begin{array}{l}\text { Extrato seco } \\
\text { desengordurado }\end{array}$ & Ultra-som - Perfil 1 & $7,95 \mathrm{a}$ & $7,92 \mathrm{a}$ & $8,83 \mathrm{~b}$ & $8,57 \mathrm{~b}$ & $8,90^{\mathrm{a}}$ & $8,37 \mathrm{a}$ & $8,78 \mathrm{a}$ & $8,92 \mathrm{a}$ & $6,44 \mathrm{~b}$ & $6,29 \mathrm{a}$ \\
\hline Proteína & Oficial & $2,89 \mathrm{a}$ & $2,40 \mathrm{a}$ & $2,02 \mathrm{a}$ & $2,25 \mathrm{a}$ & $3,15 \mathrm{a}$ & $2,36 \mathrm{a}$ & $2,46 \mathrm{a}$ & $2,56 \mathrm{a}$ & $0,77 \mathrm{a}$ & n.d. \\
\hline \multirow[t]{3}{*}{ Lipídios } & Oficial & $3,60 \mathrm{a}$ & $3,46 \mathrm{~b}$ & $3,40 \mathrm{~b}$ & $2,86 \mathrm{~b}$ & 0 & $0,46 \mathrm{~b}$ & $0,20 \mathrm{c}$ & $0,26 \mathrm{~b}$ & 0 & 0 \\
\hline & Ultra-som - Perfil 1 & $3,36 \mathrm{a}$ & $3,29 \mathrm{a}$ & $3,04 \mathrm{a}$ & $2,37 \mathrm{a}$ & 0 & $0,00 \mathrm{a}$ & $0,00 \mathrm{a}$ & $0,00 \mathrm{a}$ & 0 & 0 \\
\hline & Ultra-som - Perfil 2 & $3,49 \mathrm{a}$ & $3,42 \mathrm{~b}$ & $3,15 b$ & $2,52 \mathrm{a}$ & 0 & $0,00 \mathrm{a}$ & $0,05 \mathrm{~b}$ & $0,00 \mathrm{a}$ & 0 & 0 \\
\hline
\end{tabular}

Média de três determinações. Valores na mesma coluna com diferentes letras são significativamente diferentes $(\mathrm{P}<0.05)$. n.d.: não determinado. 
TABELA II - Teores de extrato seco desengordurado (g.100g $\left.\mathrm{g}^{-1}\right)$, proteína $\left(\mathrm{g} .100 \mathrm{~g}^{-1}\right)$, lipídios $\left(\mathrm{g} .100 \mathrm{~g}^{-1}\right)$ em leites fermentados comerciais (Y, Fp e M), bases lácteas para leites fermentados preparados em laboratório* (BL1, BL2, BL3, BL4, BL5, BL6 e BL7) analisados por métodos oficiais e por técnica de ultra-som em dois perfis (Perfil 1 e Perfil 2)

\begin{tabular}{|c|c|c|c|c|c|c|c|c|c|c|c|}
\hline & & LCI1 & LCI2 & LOI1 & LOI2 & LCD1 & LCD2 & LOD1 & LOD2 & S1 & S2 \\
\hline & & Y & $\mathrm{Fp}$ & $\mathrm{M}$ & BL1 & BL2 & BL3 & BL4 & BL5 & BL6 & BL7 \\
\hline Extrato seco & Oficial & $19,68 \mathrm{a}$ & $19,70 b$ & $11,00 \mathrm{~b}$ & $14,52 \mathrm{a}$ & $14,11 \mathrm{ab}$ & $14,54 \mathrm{a}$ & $13,63 \mathrm{a}$ & $14,26 b$ & $14,00 \mathrm{a}$ & $13,90 \mathrm{a}$ \\
\hline \multirow[t]{2}{*}{ desengordurado } & Ultra-som - Perfil 1 & $19,43 \mathrm{a}$ & $18,80 \mathrm{a}$ & $4,37 \mathrm{a}$ & $15,67 b$ & $13,90 \mathrm{a}$ & $14,33 \mathrm{a}$ & $14,10 \mathrm{~b}$ & $13,70 \mathrm{a}$ & $14,10 \mathrm{a}$ & $13,80 \mathrm{a}$ \\
\hline & Ultra-som - Perfil 2 & $20,80 \mathrm{a}$ & $20,00 \mathrm{~b}$ & $4,88 \mathrm{a}$ & $16,67 \mathrm{c}$ & $14,63 b$ & $15,30 \mathrm{a}$ & $15,07 \mathrm{c}$ & $14,63 \mathrm{c}$ & $15,10 \mathrm{~b}$ & $14,70 \mathrm{~b}$ \\
\hline \multirow[t]{3}{*}{ Proteína } & Oficial & $1,99 \mathrm{a}$ & $1,75 \mathrm{a}$ & $2,95 \mathrm{c}$ & $5,50 \mathrm{a}$ & $5,06 \mathrm{a}$ & $5,08 \mathrm{a}$ & $5,07 \mathrm{a}$ & $4,84 \mathrm{a}$ & $5,32 b$ & $5,57 \mathrm{~b}$ \\
\hline & Ultra-som - Perfil 1 & $7,24 \mathrm{~b}$ & $6,98 \mathrm{~b}$ & $1,52 b$ & $5,74 \mathrm{~b}$ & $4,99 \mathrm{a}$ & $5,22 \mathrm{a}$ & $5,12 \mathrm{a}$ & $4,98 \mathrm{~b}$ & $5,15 \mathrm{a}$ & $5,00 \mathrm{a}$ \\
\hline & Ultra-som - Perfil 2 & - & - & - & - & - & - & - & - & - & - \\
\hline \multirow[t]{3}{*}{ Lipídios } & Oficial & 0 & 0 & 0 & 0 & 0 & 0 & 0 & 0 & 0 & 0 \\
\hline & Ultra-som - Perfil 1 & 0 & 0 & - & 0 & 0 & 0 & 0 & 0 & 0 & 0 \\
\hline & Ultra-som - Perfil 2 & 0 & 0 & - & 0 & - & 0 & 0 & 0 & 0 & 0 \\
\hline
\end{tabular}

Média de três determinações. Valores na mesma coluna com diferentes letras são significativamente diferentes $(\mathrm{P}<0.05)$. * leites padronizados a 12,0\% de sólidos totais e enriquecidos com hidrolisado de caseína, leite em pó desnatado e proteína concentrada de soro.

do leite para a produção de iogurtes pode estar abaixo de $9 \%$ em iogurtes de baixo teor de gordura em até $30 \%$ em outros tipos de iogurte (Tamime, Robinson, 1999). Observaram-se diferenças significativas na determinação de extrato seco desengordurado em função do método empregado.

\section{Proteína}

Determinar o percentual de proteína é a análise mais trabalhosa. O teor de proteína dos diferentes leites variou de 2,02 g.100 g-1 (método oficial) a 3,70 g. $100 \mathrm{~g}^{-1}$ (ultrasom, Perfil 2) (Tabela I). Estes valores concordam com os publicados por Torres et al. (2000), Gonzalez et al. (2004), Duarte et al. (2005) e Noro et al. (2006).

O soro analisado pelo método oficial continha 0,77 g. $100 \mathrm{~g}^{-1}$ de proteína. As análises de proteína do soro realizadas no equipamento por ultra-som apresentaram altos valores (1,48 g. $100 \mathrm{~g}^{-1}$ a $\left.2,26 \mathrm{~g} .100 \mathrm{~g}^{-1}\right)$ em função do baixo teor de sólidos totais acarretando em erro nas determinações de proteína em amostras desta natureza.

O teor de proteína, resultado das análises oficiais, dos diferentes leites fermentados variou nos produtos comerciais de 1,75 a 2,95 g. $100 \mathrm{~g}^{-1} \mathrm{e}$, nos produtos preparados em laboratório de 4,84 a 5,57 g.100g-1 (Tabela II). Os teores de proteína dos produtos comerciais foram diferentes estatisticamente dos resultados obtidos por análise por ultrasom (Perfil 1) e muito discrepantes daqueles obtidos com o Perfil 2 (dados não apresentados). Para os produtos pre- parados em laboratório, o Perfil 1 mostrou resultados compatíveis com aqueles dos métodos oficiais. O teor de proteína de iogurtes pode ser muito variável conforme o produtor. Torres et al. (2000) relatam o teor de proteína de 4,29 g. $100 \mathrm{~g}^{-1}$ em iogurtes.

$\mathrm{Na}$ determinação de proteína verificam-se grandes discrepâncias nos resultados. Conforme a amostra existe um, dois ou mesmo não há perfil que se enquadre no valor de análise obtido pelo método oficial (Tabelas I, II e IV).

\section{Lipídios}

O teor de lipídios variou, nos diferentes leites integrais, de 2,37 g. $100 \mathrm{~g}^{-1}$ a $3,60 \mathrm{~g} .100 \mathrm{~g}^{-1}$, porém com pequenas diferenças estatísticas. Estes valores são similares ao obtidos por Garrido et al. (2001) analisando leites integrais da região de Ribeirão Preto, São Paulo e Noro et al. (2006) avaliando o efeito de fatores ambientais na produção e composição do leite em rebanhos assistidos por cooperativas no Rio Grande do Sul. Entretanto, os valores obtidos na análise do teor de lipídios em leites integrais deste trabalho são inferiores aos encontrados por Torres et al. (2000), Gonzalez et al. (2004) e Duarte et al., (2005). Nos leites desnatados, no soro e, nos leites fermentados, o teor de lipídios foi zero como esperado.

Comparar os resultados do método oficial para a análise do teor lipídios com os obtidos na técnica por ultrasom foi, sem dúvida, a tarefa mais objetiva e com menos 
desvios. Este tópico mostrou-se tão eficiente que não é possível distinguir qual dos perfis é melhor para a amostra. Assim sendo, ambos enquadram-se dentro dos desvios estatísticos aqui considerados.

\section{Densidade}

Determinar a densidade das amostras é a tarefa mais simples de todas. Não envolve reação química e a instrumentação é simples: um lacto-densímetro e uma proveta (necessita correção por meio de tabela). Ou, conforme a precisão do instrumento, uma pipeta graduada e uma balança analítica.

O leite fluido apresentou densidade na faixa de 1,030 - 1,034 g.c $\mathrm{cm}^{-3}$ enquanto o soro de leite de 1,025 1,030 g. $\mathrm{cm}^{-3}$, valores de acordo com a legislação brasileira para leites fluidos (BRASIL, 2001) e coerentes com os da literatura (Duarte et al., 2005; Walstra et al., 2006).

Nos perfis do ultra-som, o designado como Perfil 1 indicou sempre densidades menores que o Perfil 2 (Tabela I).

\section{Correlação}

A Tabela III apresenta a matriz de correlação entre os resultados das análises de extrato seco desengordurado, proteína, gordura e densidade dos diferentes leites pela metodologia oficial e ultra-som (perfis 1 e 2). Observa-se que $P=0,92$ (extrato seco desengordurado), $P=0,84$ (proteína), $P=0,99$ (gordura) e $P>0,90$ (densidade). Nos produtos fermentados, a correlação foi ligeiramente menor isto é, foi $P>0,85$ (extrato seco desengordurado). Contrariamente, o teor de proteína dos produtos fermentados não obteve correlação.

\section{CONCLUSÕES}

Os resultados deste estudo permitem concluir que os resultados da análise físico-química de alguns produtos lácteos por metodologia oficial e por ultra-som são comparáveis. Os resultados de extrato seco desengordurado, proteína, gordura e densidade obtidos por ultra-som correla-

TABELA III - Matriz de correlações* entre os resultados das análises de extrato seco desengordurado, proteína, lipídios e densidade em leites fluidos e soro de queijo e leites fermentados pela metodologia oficial e ultra-som (Perfil 1 e Perfil 2)

\begin{tabular}{|c|c|c|c|c|c|}
\hline & & & Oficial & $\begin{array}{l}\text { Ultra-som } \\
\text { Perfil } 1\end{array}$ & $\begin{array}{c}\text { Ultra-som } \\
\text { Perfil } 2\end{array}$ \\
\hline $\begin{array}{l}\text { Extrato seco } \\
\text { desengordurado }\end{array}$ & $\begin{array}{l}\text { Leites fluidos e } \\
\text { soro de queijo }\end{array}$ & $\begin{array}{l}\text { Oficial } \\
\text { Ultra-som - Perfil } 1 \\
\text { Ultra-som - Perfil } 2\end{array}$ & $\begin{array}{l}0,92 \\
0,92\end{array}$ & 0,92 & 0,92 \\
\hline Proteína & & $\begin{array}{l}\text { Oficial } \\
\text { Ultra-som - Perfil } 1 \\
\text { Ultra-som - Perfil } 2\end{array}$ & $\begin{array}{l}0,84 \\
0,84\end{array}$ & 0,84 & 0,84 \\
\hline Lipídios & & $\begin{array}{l}\text { Oficial } \\
\text { Ultra-som - Perfil } 1 \\
\text { Ultra-som - Perfil } 2\end{array}$ & $\begin{array}{l}0,99 \\
0,99\end{array}$ & 0,99 & 0,99 \\
\hline Densidade & & $\begin{array}{l}\text { Oficial } \\
\text { Ultra-som - Perfil } 1 \\
\text { Ultra-som - Perfil } 2\end{array}$ & $\begin{array}{c}0,91 \\
0,9\end{array}$ & 0,91 & 0,9 \\
\hline $\begin{array}{l}\text { Extrato seco } \\
\text { desengordurado }\end{array}$ & Leites fermentados & $\begin{array}{l}\text { Oficial } \\
\text { Ultra-som - Perfil } 1 \\
\text { Ultra-som - Perfil } 2\end{array}$ & $\begin{array}{l}0,85 \\
0,86\end{array}$ & 0,85 & 0,86 \\
\hline Proteína & & $\begin{array}{l}\text { Oficial } \\
\text { Ultra-som - Perfil } 1 \\
\text { Ultra-som - Perfil } 2\end{array}$ & $\begin{array}{l}-0,21 \\
-0,23\end{array}$ & $-0,21$ & $-0,23$ \\
\hline
\end{tabular}

$* \mathrm{P}<0,05$ 
TABELA IV - Perfis* de análise do equipamento ultra-som que melhor se enquadram aos resultados obtidos pelos métodos oficiais

\begin{tabular}{lll}
\hline Análise & Produto lácteo & Perfil \\
\hline Extrato seco desengordurado & Leites Integrais (orgânico e comercial) & Perfil 1 \\
& Leites Desnatados (orgânico e comercial) & Perfil 2 \\
& Soro de queijo & Perfil 2 \\
& Leites Fermentados & Perfil 2 \\
& Leites Enriquecidos & Perfil 2 \\
& Leites Integrais (orgânico e comercial) & Perfil 2 \\
Proteína & Leites Desnatados (orgânico e comercial) & Perfil 2 \\
& Soro de queijo & Nenhum (aparelho necessita calibração) \\
& Leites Fermentados & Nenhum (aparelho necessita calibração) \\
& Leites Enriquecidos & Perfil 2 \\
& Leites Integrais (orgânico e comercial) & Perfis 1 e 2 \\
Lipídios & Leites Desnatados (orgânico e comercial) & Perfis 1 e 2 \\
& Soro de queijo & Perfis 1 e 2 \\
& Leites Fermentados & Perfis 1 e 2 \\
& Leites Enriquecidos & Perfis 1 e 2 \\
& Leites Integrais (orgânico e comercial) & Perfil 1 \\
& Leites Desnatados (orgânico e comercial) & Perfil 2 \\
Soro de queijo & Perfil 1 \\
\hline
\end{tabular}

*Perfil 1 a Perfil 2, equivalentes a leite pasteurizado e cru, respectivamente.

cionam-se àqueles das análises oficiais em leites, soro de queijo e produtos fermentados, exceto proteína nos leites fermentados.

Recomenda-se que conforme a amostra em análise, um perfil de análise do aparelho deve ser ajustado. O perfil que melhor se enquadra para cada amostra é resumido na Tabela IV.

$\mathrm{O}$ aparelho de ultra-som configura-se como um bom método, porém as análises por métodos oficiais não devem ser abandonadas. Observou-se claramente com estes resultados que antes de depositar total confiança em equipamento que emprega novas tecnologias faz-se necessário construir-se um estudo como o descrito neste artigo, para poder identificar as limitações do aparelho e poder, então, calibrálo da melhor forma possível.

Os resultados deste trabalho exploratório sugerem a grande necessidade de se realizar um estudo com número grande de amostras a fim de validar as conclusões obtidas.

\section{AGRADECIMENTOS}

Agradecemos ao CNPq pelo suporte financeiro para o desenvolvimento deste trabalho (Processo 475396/20049) e à Fapesp (05/57599-5).

\section{ABSTRACT \\ Determination of the physical-chemical composition of dairy products: exploratory study to compare the results obtained by classic methodology and by ultra-sound}

The present paper aims to compare the official methods of physical-chemical determination of dairy products (defatted dry matter, protein, fat and density) with methodology using ultra-sound. Different products were analyzed: milks (integral and skimmed conventional and organic), commercial fermented milks and dairy milk bases prepared in laboratory and whey totalizing twenty dairy products of different characteristics. The method using ultra-sound is fast and the results are correlated with those of the official analyses. However, the operator of the equipment should be attentive to employ a specific profile of the equipment according to the analysis to be carried out and, to calibrate the equipment based in the information obtained by the official analyses. The results of this exploratory article suggest the need to perform a study with a great number of samples in order to validate the obtained conclusions. The evidences described in this article are 
important for the Brazilian industry of dairy products.

UNITERMS: Milk. Dairy products. Yoghurt. Physicalchemical quality. Ultra-sound. Milk.

\section{REFERÊNCIAS BIBLIOGRÁFICAS}

ALMEIDA, K.E. Modelagem da atividade acidificante de bactérias probióticas em misturas leite-soro. São Paulo, 2005. 85p. [Monografia para exame geral de qualificação para doutorado. Faculdade de Ciências Farmacêuticas Universidade de São Paulo].

ATHERTON, H.V.; NEWLANDER, J.A. Chemistry and testing of dairy products. 4.ed. Westport: Avi, 1981. p.395.

BRASIL. Ministério da Agricultura, Pecuária e Abastecimento.Legislação. Sislegis. Instrução Normativa SDA n.22, 14 de abril de 2003. Oficializa os métodos analíticos oficiais físico-químicos, para controle de leite e produtos lácteos, em conformidade com o anexo desta Instrução Normativa, determinando que sejam utilizados no Sistema de Laboratório Animal do Departamento de Defesa Animal. Disponível em: $<$ http://extranet.agricultura.gov.br/ sislegis-consulta/consultarLegislacao.do? operacao= visualizar\&id $=399>$. Acesso em: 6 dez. 2006.

BRASIL. Ministério da Agricultura, Pecuária e Abastecimento. Legislação. Sislegis. Instrução Normativa n.51, de 18 de setembro de 2002.Aprova os regulamentos técnicos de produção, identidade e qualidade do leite tipo A, do leite tipo $\mathrm{B}$, do leite tipo $\mathrm{C}$, do leite pasteurizado e do leite cru refrigerado e o regulamento técnico da coleta de leite cru refrigerado e seu transporte a granel. Disponível em: $<$ http:/ /extranet.agricultura.gov.br/ sislegis-consulta/ consultarLegislacao.do?operacao=visualizar\&id $=8932>$. Acesso em: 6 dez. 2006.

DUARTE, L.M.D.; STUMPF JUNIOR, W.; FISCHER, V.; SALLA, L.E. Efeito de diferentes fontes de gordura na dieta de vacas Jersey sobre o consumo, a produção e a composição do leite. Rev. Bras. Zootec., v.34, n.6, p.20202028, 2005.

FURTADO, M.M.; NETO, J.P.M. Tecnologia de queijos: manual técnico para produção industrial de queijos. São Paulo: Dipemar,1994. 118p.
GARRIDO, N.; MORAIS, J.M.T.; BRIGANTI, R.C.; OLIVEIRA, M.A.; BERGAMINI,A.M.M.; OLIVEIRA, S.A.V.; FÁVARO, R.M.D. Avaliação da qualidade físicoquímica e microbiológica de leite pasteurizado proveniente de mini e micro-usinas de beneficiamento da região de Ribeirão Preto, São Paulo. Rev. Inst. Adolfo Lutz, v.60, n.2, p.141-146, 2001.

GONZALEZ, H.; FISCHER, V., RIBEIRO, M.E.R.; GOMES, J.F.; STUMPF JUNIOR, W.; SILVA, M.A. Avaliação da qualidade do leite na bacia leiteira de Pelotas, RS. Efeito dos meses do ano. Rev. Bras. Zootecnia, v.33, n.6, p.1531-1543, 2004.

LACTOSCAN. Ultrasonic Milk Analysers. Disponível em: $<$ http://www.lactoscan.com/faq.html $>$. Acesso em: $1 \mathrm{dez}$. 2006.

McCLEMENTS, D.J. Advances in the application of ultrasound in food analysis and processing. Trends Food Sci. Technol., v.6, n.9, p.293-299, 1995.

NORO, G.; GONZALEZ, F.D.; CAMPOS, R.; DURR, J.W. Fatores ambientais que afetam a produção e a composição do leite em rebanhos assistidos por cooperativas no Rio Grande do Sul. Rev. Bras. Zootecnia, v.35, n.3 (supl.), p.1129-1135. 2006.

POOVEY, M.J.W.; MASON, T.J. Ultrasound in food processing. New York: Blackie Academic Professional, 1998. 282p.

PRUDENCIO, E.S.; BENEDET, H.D. Utilization of cheese whey for the production of soybean's hydro-soluble extract. Ciênc. Tecnol. Aliment., v.19, n.1, p.97-101, 1999.

TAMIME, A.Y.; ROBINSON, R.K. Yoghurt: science and technology. 2.ed. Boca Raton: CRC, 1999. 368p.

VERRUMA, M.R.; SALGADO, J.M. Análise química do leite de búfala em comparação ao leite de vaca. Scientia Agricola, v.51, n.1, p.131-137, 1994.

WALSTRA, P.; WOUTERS, J.T.M.; GEURTS, T.J. Dairy science and technology. New York: CRC, 2006. p.166167.

Recebido para publicação em 15 de dezembro de 2006. Aceito para publicação em 20 de agosto de 2007. 